\title{
Risk of acute kidney injury and survival in patients treated with Metformin: an observational cohort study
}

Samira Bell ${ }^{1 *+} \mathbb{D}$, Bassam Farran ${ }^{3 \dagger}$, Stuart McGurnaghan ${ }^{3}$, Rory J. McCrimmon ${ }^{4}$, Graham P Leese ${ }^{5}$, John R Petrie ${ }^{6}$, Paul McKeigue ${ }^{7}$, Naveed Sattar ${ }^{6}$, Sarah Wild ${ }^{7}$, John McKnight ${ }^{8}$, Robert Lindsay ${ }^{6}$, Helen M. Colhoun ${ }^{3}$ and Helen Looker ${ }^{2}$

\begin{abstract}
Background: Whether metformin precipitates lactic acidosis in patients with chronic kidney disease (CKD) remains under debate. We examined whether metformin use was associated with an increased risk of acute kidney injury (AKI) as a proxy for lactic acidosis and whether survival among those with AKI varied by metformin exposure.

Methods: All individuals with type 2 diabetes and available prescribing data between 2004 and 2013 in Tayside, Scotland were included. The electronic health record for diabetes which includes issued prescriptions was linked to laboratory biochemistry, hospital admission, death register and Scottish Renal Registry data. AKl events were defined using the Kidney Disease Improving Global Outcomes criteria with a rise in serum creatinine of at least $26.5 \mathrm{\mu mol} / \mathrm{l}$ or a rise of greater than $150 \%$ from baseline for all hospital admissions. Cox Regression Analyses were used to examine whether person-time periods in which current metformin exposure occurred were associated with an increased rate of first AKI compared to unexposed periods. Cox regression was also used to compare 28 day survival rates following first AKl events in those exposed to metformin versus those not exposed.

Results: Twenty-five thousand one-hundred fourty-eight patients were included with a total person-time of 126,904 person years. 4944 (19.7\%) people had at least one episode of AKI during the study period. There were 32.4 cases of first AKI/1000pyrs in current metformin exposed person-time periods compared to 44.9 cases/1000pyrs in unexposed periods. After adjustment for age, sex, diabetes duration, calendar time, number of diabetes drugs and baseline renal function, current metformin use was not associated with AKI incidence, HR 0.94 (95\% Cl 0.87, 1.02, $p=0.15)$. Among those with incident AKI, being on metformin at admission was associated with a higher rate of survival at 28 days ( $H R$ 0.81,95\% Cl 0.69, 0.94, $p=0.006$ ) even after adjustment for age, sex, pre-admission eGFR, $\mathrm{HbA}_{1 c}$ and diabetes duration.
\end{abstract}

Conclusions: Contrary to common perceptions, we found no evidence that metformin increases incidence of AKI and was associated with higher 28 day survival following incident AKI.

Keywords: Acute kidney injury, Diabetes, Epidemiology, Metformin, Survival

\footnotetext{
* Correspondence: samira.bell@nhs.net

${ }^{\dagger}$ Equal contributors

${ }^{1}$ Renal Unit, Ninewells Hospital, Dundee DD1 9SY, UK

Full list of author information is available at the end of the article
}

(c) The Author(s). 2017 Open Access This article is distributed under the terms of the Creative Commons Attribution 4.0 International License (http://creativecommons.org/licenses/by/4.0/, which permits unrestricted use, distribution, and reproduction in any medium, provided you give appropriate credit to the original author(s) and the source, provide a link to the Creative Commons license, and indicate if changes were made. The Creative Commons Public Domain Dedication waiver (http://creativecommons.org/publicdomain/zero/1.0/) applies to the data made available in this article, unless otherwise stated. 


\section{Background}

Metformin is a biguanide which has been used as first line therapy for the treatment of type 2 diabetes in the United Kingdom since the 1960s. In addition to its effectiveness as a treatment for type 2 diabetes, there is increasing evidence of its beneficial cardiovascular effects [1-6]. There is, however, considerable debate regarding its use in patients with chronic kidney disease (CKD), defined as an estimated Glomerular Filtration Rate (eGFR) of less than $60 \mathrm{ml} / \mathrm{min} /$ $1.73^{2}$. Guidelines pertaining to metformin prescribing and renal impairment vary. The United States Food and Drug Administration (FDA) previously stated that metformin was contraindicated in males with a serum creatinine above $132.6 \mu \mathrm{mol} / \mathrm{l}$ and females above $123.8 \mu \mathrm{mol} / \mathrm{l}$ or abnormal creatinine clearance [7]. However, following a recent review of the literature, these recommendations were revised to indicate that metformin can now be used safely in patients with mild renal impairment (eGFR $45-60 \mathrm{ml} / \mathrm{min} / 1.73^{2}$ ) and in some with moderate renal impairment (eGFR $<45 \mathrm{ml} / \mathrm{min} / 1.73^{2}$ ) [8]. The National Institute for Health and Care Excellence (NICE) in the UK allows prescribing of metformin in patients with an eGFR of less than $60 \mathrm{ml} / \mathrm{min} / 1.73^{2}$ but recommends that the dose is reduced in patients with an eGFR of less than $45 \mathrm{ml} / \mathrm{min} / 1.73^{2}$ (or serum creatinine of greater than $132.6 \mu \mathrm{mol} / \mathrm{l}$ ) and metformin discontinued if eGFR is less than 30 or serum creatinine greater than $150.3 \mu \mathrm{mol} / \mathrm{l}$ [9]. Current contraindications therefore exclude its use in a large proportion of patients with CKD [10]. Following the FDA's announcement, the European Medicines Agency (EMA) have also now announced that metformin-containing medicines can be used in patients with moderately reduced renal function (eGFR 30 to $59 \mathrm{ml} / \mathrm{min} / 1.73^{2}$ ) [11].

The advent of a universally agreed serum creatinine based definition for AKI allows identification of even mild (Stage 1) AKI without relying on hospital coding systems [12] allowing assessment of renal safety in patients with CKD.

The present study therefore aimed to examine whether current metformin use was associated with an increased rate of AKI as a proxy for lactic acidosis compared to non-use and to establish whether metformin exposure affected survival in patients with AKI.

\section{Methods}

\section{Study population}

All adults over 18 between the 1st of January 2004 and 31st of December 2013 with type 2 diabetes and available prescribing data who were resident or died in the NHS Tayside region, Scotland formed the study cohort.

\section{Ethical statement}

Anonymised record linkage was conducted according to Health Informatics Centre (HIC), University of Dundee [13] Standard Operating Procedure (SOP). The Tayside Research Ethics Committee does not require submission of individual studies that follow this SOP which is Caldicott Guardian approved.

\section{Data sources}

Data were linked using HIC [13], University of Dundee. HIC enables anonymised health record linkage from the population of Tayside (400000), Scotland, using a unique identifying Community Health Index $(\mathrm{CHI})$ number. Data were linked between the following datasets: Scottish Morbidity Record of hospital admissions (SMR01); laboratory results, medicines dispensed by community pharmacies, the Scottish Care Initiative-Diabetes Collaboration (SCI-DC) and the Scottish Renal Registry (SRR). SMR01 provides information on age, sex, postcode and admission and discharge dates. Creatinine measurements were obtained from the laboratory system. SCI-DC provided information on diabetes type and date of diagnosis. The number of dispensed prescriptions over the previous year prior to admission from community pharmacies, and exposure to medications that predispose to renal impairment (non-steroidal anti-inflammatory drugs (NSAIDs), Cox-2 inhibitors, ACE-inhibitors and Angiotensin-II receptor antagonists), were ascertained from dispensed prescribing data. This dataset comprises of all community dispensed prescribing from community pharmacies in the Tayside region of Scotland. Patients receiving chronic dialysis or post renal transplant were identified using the SRR.

\section{Outcomes}

All hospital admissions during follow up were evaluated for the difference between the peak in-hospital and preadmission serum creatinine. AKI severity was defined using the Kidney Disease Improving Global Outcomes (KDIGO) creatinine based criteria. AKI was defined as the rise in serum creatinine of at least $26.5 \mu \mathrm{mol} / \mathrm{l}$ or a serum creatinine of greater than $150 \%$ of baseline serum creatinine during admission [12]. Baseline creatinine was defined as the median of all creatinine measurements between 28 and 56 days prior to hospitalisation. Cases were excluded if a baseline creatinine was not measured. Estimated GFR was calculated using the Modification of Diet in Renal Disease (MDRD) 4 formula [14]. The primary outcome for the survival analysis was all-cause mortality within 28 days from the day of admission.

\section{Statistical methods}

All type 2 diabetes patients who were at least 18 years old at diagnosis and were observable for drug prescriptions at 
some point during the study period were included. A patient was considered observable if they had records of drug prescriptions, with gaps of up to 180 days between prescriptions allowed. Their entry date was calculated as the latest of their date of diagnosis of diabetes, study entry date (1/1/2004), and their drug observability (between study start date and study end date (31/12/2013)). Followup was censored at the earliest of death, study end date, unobservability, or AKI event. The data was then split longitudinally into 28 day time slices, meaning each 28 days a patient contributed to the study results in one row in our data set. This allowed us to use time-updated covariates (eGFR, number of diabetes drugs being taken, diabetes duration, calendar time, ever/never metformin use, and $\mathrm{HbA1c}$ ). If more than one measurement (such as eGFR or $\mathrm{HbA}_{1 \mathrm{c}}$ ) fell into the same time slice, the median was taken. Patients who contributed less than 28 days of follow-up were excluded. All observability stretches were extended by 90 days as drug observability ceases during hospitalisation. Drugs were identified by their Anatomical Therapeutic Chemical (ATC) codes, and drug unobservability meant a patient had not had a prescription of any drug for more than 180 days.

Baseline characteristics (ie those identified closest to study entry date) were displayed as mean and standard deviation (SD) or median and interquartile range (IQR) for continuous variables depending on distribution. Categorical variables were displayed as number and percentage.

\section{Survival analysis}

Cox regression analyses, comparing AKI rates in persontime periods on metformin with AKI rates in person time periods not on metformin, were used to calculate hazard ratios (HR) and 95\% confidence intervals adjusted for confounders. Confounders were selected based on literature, guidelines and clinical expertise and were age, sex, diabetes duration, baseline renal function, calendar time and number of diabetes drug classes $[12,15]$. All analyses were carried out in R. Sensitivity analysis was performed using "ever" versus "never" exposure in place of current exposure where "ever" was defined as at least one prescription for metformin during the study period.

\section{Results}

Between 1st of January 2004 and 31st of December 2013, there were 25,148 patients with Type 2 diabetes in the Tayside region of Scotland forming the study cohort. 14,622 of these patients were treated with metformin at some point during the study period and 10,526 patients were never on metformin during the study period. Total person-time was 126,904 person years (pyrs) of which 60,738 pyrs were exposed to metformin. Median duration of follow-up was 8.1 years IQR (5.2-10.0). Demographic characteristics of the study population at the study midpoint (1st July 2008) are described in Table 1. The analysis conducted here is a time updated analysis of rates in person-time periods (rather than persons) associated with metformin exposure compared to person-time periods without exposure therefore we show the characteristics of person-time periods associated with current metformin exposure compared to person-time periods without current exposure in Table 2. Metformin exposure periods occurred at younger ages, higher $\mathrm{HbA}_{1 \mathrm{c}}$, longer duration of diabetes and were associated with higher eGFR, $p<0.0002$.

During follow-up, 4944 people had at least one episode of AKI during the study period. Of these AKI events, 4352 were Stage 1, 140 Stage 2 and 452 Stage 3 AKI events. Only person-time periods to the first event were included in analyses. The characteristics at entry into the study of those persons who had an event at any time during follow up versus those who did not are shown in Table 3. Patients who had any AKI event had lower eGFR at entry to the study than those who never developed an event (median $58 \mathrm{ml} / \mathrm{min} / 1.73^{2}$ IQR 46-70 vs $73 \mathrm{ml} / \mathrm{min} / 1.73^{2}$ IQR $61-88$ ). AKI was strongly associated with pre-admission eGFR (Table 4).

Overall incidence of AKI was 39.0 cases/1000 pyrs. There were 32.4 cases of AKI/1000pyrs in person-time periods with current metformin use compared to 44.9

Table 1 Demographic characteristics of cohort at study midpoint 1st July 2008, $n=12,373$

\begin{tabular}{ll}
\hline Age in years & \\
Sex (M) (\%) & $68.2(59.2-75.9)$ \\
Metformin Use (\%) & $6636(54)$ \\
Diabetes Duration in years ${ }^{\mathrm{a}}$ & $5975(48)$ \\
Number of diabetes drug classes prescribed (\%) & $5.48(2.50-9.91)$ \\
0 & \\
1 & $4187(33.8)$ \\
2 & $4517(36.5)$ \\
3 & $2943(23.8)$ \\
4 & $671(5.4)$ \\
5 & $53(0.4)$ \\
eGFR category (\%) & $2(0.02)$ \\
$>60$ & \\
$30-59$ & $8926(72.1)$ \\
$<29$ ml/min/1.73 ${ }^{2}$ & $2574(20.8)$ \\
Missing & $180(1.5)$ \\
HbA ${ }_{1 C} \%$ & $693(5.6)$ \\
(mmol/mol) & $7.0(6.3-7.9)$ \\
ACE inhibitor or ARB Use (\%) & $53(45-63)$ \\
NSAID or Cox-2 inhibitor use (\%) & $5074(41 \%)$ \\
\hline
\end{tabular}

${ }^{\mathrm{a}}$ Median \& IQR 
Table 2 Summary patient characteristics by metformin exposure status

\begin{tabular}{|c|c|c|}
\hline & $\begin{array}{l}\text { Metformin exposed } \\
\text { periods }\end{array}$ & $\begin{array}{l}\text { Metformin unexposed } \\
\text { periods }\end{array}$ \\
\hline & & \\
\hline Age (Years) ${ }^{a}$ & $65.7(57.3-73.5)$ & $70.2(61.1-78.1)$ \\
\hline $\mathrm{HbA}_{1 c} \%$ & $7.3(6.7-8.3)$ & $6.7(6.2-7.6)$ \\
\hline$(\mathrm{mmol} / \mathrm{mol})^{a}$ & $56(50-67)$ & $50(44-60)$ \\
\hline $\begin{array}{l}\text { Diabetes Duration } \\
\text { (years) }^{\text {a }}\end{array}$ & $6.9(3.7-11.2)$ & $4.3(1.8-8.9)$ \\
\hline \multicolumn{3}{|l|}{ eGFR category (\%) } \\
\hline$>60$ & $44,830.6(73.8)$ & 39,332.4 (59.4) \\
\hline $30-60$ & $12,575.1(20.7)$ & $18,775.3(28.3)$ \\
\hline$<30 \mathrm{ml} / \mathrm{min} / 1.73^{2}$ & $236.8(0.4)$ & $1592.7(2.4)$ \\
\hline ACE/ARB use (\%) & $25,572.6(42)$ & $21,827.7(33)$ \\
\hline NSAID use (\%) & $5967.4(10)$ & $6140.8(9)$ \\
\hline
\end{tabular}

cases/1000pyrs during person-time periods in which metformin was not being used. Severity of diabetes was adjusted for by adjusting for diabetes duration and number of diabetes medicines. Current metformin use was associated with a lower AKI rate, HR 0.76 (95\% CI 0.70, $0.82, p<0.0001)$ after adjustment for sex, current age, current diabetes duration, and current number of diabetes drugs. When further adjusted for baseline renal function, current metformin use was no longer associated with any difference in AKI rate, HR 0.94 (95\% CI 0.87, 1.02, $p=0.15)$. After including current or "ever" metformin use, person-time periods with current or "ever" exposure

Table 3 Characteristics of patients developing/ not developing AKI at entry into study

\begin{tabular}{|c|c|c|}
\hline & $\begin{array}{l}\text { AKl event during } \\
\text { follow-up } \\
(n=4944)\end{array}$ & $\begin{array}{l}\text { No AKI event during } \\
\text { follow-up } \\
(n=20,204)\end{array}$ \\
\hline Age (Years) ${ }^{a}$ & $71.7(64.7-78.3)$ & $63.4(54.2-72.1)$ \\
\hline Male Sex (\%) & $2694(54.5)$ & $11,031(54.6)$ \\
\hline $\mathrm{HbA}_{1 \mathrm{c}} \%$ & $7.2(6.4-8.3)$ & $7.0(7.4-8.4)$ \\
\hline$(\mathrm{mmol} / \mathrm{mol})^{\mathrm{a}}$ & $55(46-67)$ & $53(45-68)$ \\
\hline Diabetes Duration (years) ${ }^{a}$ & $0(0-3)$ & $3.3(0-9)$ \\
\hline \multicolumn{3}{|c|}{ Number of diabetes drug classes (\%) } \\
\hline 0 & $2583(52)$ & $14,212(70)$ \\
\hline 1 & $1617(33)$ & $4471(22)$ \\
\hline 2 & $706(14)$ & $1438(7)$ \\
\hline 3 & $27(0.5)$ & $76(0.4)$ \\
\hline 4 & 1 & 6 \\
\hline 5 & 0 & 1 \\
\hline ACE/ARB use (\%) & $1505(30)$ & $4667(23)$ \\
\hline NSAID use (\%) & $474(10)$ & $2079(10)$ \\
\hline
\end{tabular}

${ }^{\mathrm{a}}$ Median \& IQR to metformin were associated with higher rates of AKI than person-time periods with no current or prior exposure; HR 1.13 (95\%CI 1.05, 1.22, $p=0.001)$.

At study midpoint only $1.5 \%$ of people with an eGFR $<30$ were taking metformin compared to $72 \%$ of people with an eGFR $>60$. Clearly since current eGFR is a strong correlate of metformin exposure and predicts future AKI events, disentangling drug effects from allocation effects is difficult and negative confounding by allocation could explain the hazards ratio (HR) observed. In addition to adjusting for baseline eGFR in the Cox regression, we also examined whether, among strata of person-time periods defined by baseline eGFR, whether there was any evidence of an effect of metformin. We found no evidence of increased rates of AKIeven where baseline eGFR was $<30$, the rates of events in person-time periods exposed to metformin were not greater than those unexposed to metformin (Table 5). Furthermore we conducted a sensitivity analysis where we adjusted for lagged eGFR - i.e. for each time periods we included a time updated covariate which was eGFR 6 months prior to that time period as distinct from the baseline eGFR as that may have long preceded that person-time period. This analysis allows for a fuller adjustment of the effect of prevailing eGFR on the probability of metformin exposure. In this analysis the HR for current metformin exposure was 0.85 (95\%CI 0.78 , $0.92), p<0.0001$.

Note that since it could be argued that the probability of subsequent exposure to metformin (either for the first time or repeat prescription) may be altered when an AKI event has occurred, person- time was right censored at the first AKI event for this part of the analyses.

\section{Survival}

Table 6 show the characteristics of those AKI events where there was current metformin exposure compared to events not associated with current exposure. Of patients with AKI, 844 died within 28 days of admission. Death rate was 23.5 (per 1000 pyears of follow-up): 7.9 in patients on metformin vs 15.6 in patients not on metformin per 1000 pyears. Conditional on the AKI event occurring, metformin use at admission was associated with a lower risk of death at 28 days (HR 0.81, 95\% CI $0.69,0.94, p=0.006$ ) even after adjustment for age, sex, pre-admission eGFR, $\mathrm{HbA}_{1 \mathrm{c}}$ and diabetes duration. Following further adjustment for use of ACE inhibitor or ARB, use of NSAIDs or Cox-2 inhibitors and number of prescribed medicines as a proxy for co-morbidity, this effect persists (HR 0.82, 95\% CI 0.70, 0.95, $p=0.01$ ). When examining longer term mortality to the end of 2013 in those who had experienced an AKI event, risk of death subsequent to an AKI event not on metformin was higher HR 1.32 (95\%CI 1.23, 1.43, $p<0.0001)$ than 
Table 4 Distribution of AKI incidence by baseline eGFR and AKI stage

\begin{tabular}{|c|c|c|c|c|c|c|c|c|c|}
\hline \multirow{3}{*}{ AKI Stage } & \multicolumn{9}{|c|}{$\mathrm{eGFR}\left(\mathrm{ml} / \mathrm{min} / 1.73^{2}\right)$} \\
\hline & \multicolumn{3}{|l|}{$<30$} & \multicolumn{3}{|l|}{$30-60$} & \multicolumn{3}{|l|}{$>60$} \\
\hline & $n$ & $\begin{array}{l}\text { Person time } \\
\text { (years) }\end{array}$ & $\begin{array}{l}\text { Incidence rate } \\
\text { (per } 1000 \text { person-years) }\end{array}$ & $n$ & $\begin{array}{l}\text { Person time } \\
\text { (years) }\end{array}$ & $\begin{array}{l}\text { Incidence rate } \\
\text { (per } 1000 \text { person-years) }\end{array}$ & $n$ & $\begin{array}{l}\text { Person time } \\
\text { (years) }\end{array}$ & $\begin{array}{l}\text { Incidence rate } \\
\text { (per } 1000 \text { person-years) }\end{array}$ \\
\hline 1 & 439 & 1829 & 240 & 2187 & 31,350 & 70 & 1717 & 84,163 & 20 \\
\hline 2 & 16 & 1829 & 8.7 & 43 & 31,350 & 1.3 & 81 & 84,163 & 1.0 \\
\hline 3 & 167 & 1829 & 91 & 142 & 31,350 & 4.5 & 129 & 84,163 & 1.5 \\
\hline
\end{tabular}

risk of death with AKI treated with metformin HR 1.15 (95\%CI 1.06, 1.25, $p=0.002$ ) after adjustment for age, sex, baseline renal function, $\mathrm{HbA}_{1 \mathrm{c}}$ and diabetes duration.

\section{Discussion}

In this large cohort of over 25,000 patients with Type 2 diabetes, we found no evidence of any adverse effect of current metformin use on AKI incidence or on survival following AKI across different eGFR strata. We have shown risk of AKI does not differ during person-time periods where there was no current metformin exposure compared to those in which there was current metformin exposure.

Strengths of our study include the large cohort size with high metformin use. We identified our cohort using the SCI-Diabetes system. This system is used to record all diabetes clinical care in Scotland thereby capturing 99\% of patients with diabetes [16]. Furthermore, prescribing data was obtained from pharmacy dispensed prescriptions (covering all pharmacies in the Tayside region) rather than prescriptions alone increasing reliability that the medicines are actually being taken. AKI was defined using the KDIGO creatinine based criteria from laboratory data that are only available at regional level [12].

Observational pharmaco-epidemiology studies have to contend with various potential biases or confounders. The most difficult bias for this study is negative confounding by allocation wherein those with a lower eGFR are more likely to develop AKI but less likely to be exposed to metformin. We attempted to address this by adjustment for eGFR in a number of ways and by conducting analyses by different strata of eGFR. None of the analyses showed any suggestion of an adverse effect. Since there are unlikely to be randomised trials of

Table 5 Hazard ratios (95\% CI) for AKI associated with metformin exposure compared to non-exposure by baseline eGFR

\begin{tabular}{llll}
\hline eGFR $\left(\mathrm{ml} / \mathrm{min} / 1.73^{2}\right)$ & $<30$ & $30-60$ & $>60$ \\
\hline Number of events & 88 & 733 & 681 \\
$\mathrm{HR}(95 \% \mathrm{Cl})$ & $0.45(0.10,1.91)$ & $0.80(0.66,1.0)$ & $0.76(0.62,0.95)$ \\
$\mathrm{p}$ & 0.28 & 0.05 & 0.01 \\
\hline
\end{tabular}

allocating metformin to those with low eGFR to assess safety, this observational study provides useful reassurance that we cannot see any adverse safety signals in the data that would warrant a change to the current guidelines. If anything the data suggest that the current guidelines may be too stringent and could be relaxed further. We used multivariable analysis to adjust for important clinical confounders in view of the difference between the metformin users and the non-metformin users. Furthermore, our data may not be applicable to other populations as the Tayside region of Scotland lacks ethnic diversity and is predominantly of European ancestry. In addition, we were unable to use direct data on co-morbidity due to problems of under reporting [17]. We therefore used number of prescribed medications prior to admission which has been shown to correlate well with co-morbidity [18]. A further limitation of our

Table 6 Characteristics of patients who developed AKI during follow-up $(n=4944)$

\begin{tabular}{|c|c|c|}
\hline & $\begin{array}{l}\text { Metformin exposed } \\
\text { AKI event }\end{array}$ & $\begin{array}{l}\text { AKI event without concurrent } \\
\text { metformin exposure }\end{array}$ \\
\hline & $(n=1972)$ & $(n=2972)$ \\
\hline Age (Years) ${ }^{a}$ & $73.6(65.7-79.4)$ & $77.6(70.4-83.7)$ \\
\hline Male Sex (\%) & $1161(58.9)$ & $1533(51.6)$ \\
\hline $\mathrm{HbA}_{1 c} \%$ & $7.2(6.5-8.3)$ & $6.8(6.2-7.9)$ \\
\hline$(\mathrm{mmol} / \mathrm{mol})^{a}$ & $55(48-67)$ & $51(44-63)$ \\
\hline $\begin{array}{l}\text { Diabetes Duration } \\
\text { (years) }^{a}\end{array}$ & $9.15(5.11-13.85)$ & $7.50(3.30-13.76)$ \\
\hline \multicolumn{3}{|c|}{ Number of diabetes drug classes (\%) } \\
\hline 0 & $13(0.7)$ & $1745(58.7)$ \\
\hline 1 & $830(42.1)$ & 1049 (35.3) \\
\hline 2 & $897(45.5)$ & $162(5.5)$ \\
\hline 3 & $212(10.8)$ & $16(0.5)$ \\
\hline 4 & $19(1.0)$ & $0(0.0)$ \\
\hline 5 & $1(0.1)$ & $0(0.0)$ \\
\hline \multicolumn{3}{|l|}{ CKD category (\%) } \\
\hline$>60$ & $941(47.7)$ & $986(33.2)$ \\
\hline $30-59$ & $896(45.4)$ & $1476(49.37)$ \\
\hline$<29 \mathrm{ml} / \mathrm{min} / 1.73^{2}$ & $130(6.6)$ & $492(16.6)$ \\
\hline
\end{tabular}


study was that we were unable to account for over the counter NSAID use in our population.

Reported incidence rates of metformin associated lactic acidosis are in fact very low further supporting its more widespread use. A Cochrane review showed no cases of fatal or non-fatal lactic acidosis in 70, 490 patient- years of metformin use [19]. Incidence rates of MALA were 3.3 per 100,000 person-years in a nested case control analysis of 50,048 patients from the United Kingdom General Practice Research Database compared with 4.8 per 100,000 person-years among sulphonylurea users [20]. Several studies have shown use of metformin in patients with renal impairment thereby suggesting non-adherence to guidelines [21-25]. In a subgroup analysis of 6960 patients with eGFR $45-60 \mathrm{ml} / \mathrm{min} / 1.73^{2}$ from a Swedish cohort of 51, 675 patients, there was a significantly lower risk of acidosis/ serious infection in patients on metformin and a slightly higher but insignificant risk in the subgroup of 2044 patients with eGFR of 30$45 \mathrm{ml} / \mathrm{min} / 1.73^{2}$ [2]. A systematic review examining patients with CKD demonstrated the safety of metformin in patients with stable CKD (eGFR $>30 \mathrm{ml} / \mathrm{min} /$ $1.73^{2}$ ) including 150,000 patients. This concluded that rates of lactic acidosis were low and similar to that of sulphonylureas [26]. A more recent systematic review showed similar results suggesting that risk of lactic acidosis is low and indistinguishable from background risks and that available evidence supported expansion of metformin in patients with CKD with appropriate dose reduction and follow-up [27].

Despite almost 60 years of metformin use, there is a lack of pharmacokinetic studies of metformin in patients with CKD. Metformin inhibits the mitochondrial respiratory chain. This impairs energy metabolism aerobically leading to increased anaerobic metabolism thereby generating lactate [28]. Metformin is eliminated unchanged by the kidney therefore it can accumulate in patients with renal impairment increasing the risk of lactic acidosis. In a small study of 15 patients administered $850 \mathrm{mg}$ of metformin, mild CKD (creatinine clearance, $60-90 \mathrm{~mL} / \mathrm{min}$ ) was associated with $23 \%$ to $33 \%$ reductions in medication clearance and moderate $\mathrm{CKD}(30-60 \mathrm{~mL} / \mathrm{min})$ with $74 \%$ to $78 \%$ reductions [29]. Whilst safety of metformin has been shown in patients with mild renal impairment, dose reduction is advisable. Further pharmacokinetic studies are required to establish safe dosing in patients with moderate to severe renal impairment.

It has previously been shown in animal models that metformin exerts a nephrotoxic effect [30]. However, there is a lack of data in humans to support this. A recent retrospective cross sectional study showed that in a small number of patients, with previously normal renal function, admitted with AKI, metformin use was associated with both lactic acidosis and worsening AKI in a dose related manner. They did not, however, demonstrate a difference in survival or need for RRT [31].

There is increasing evidence that AKI is associated with increased mortality even with stage 1 [32-34] AKI. Our data found that survival rates were higher in patients with AKI previously treated with metformin compared to patients with AKI not previously on metformin. This is in line with several previous observational studies in which lower event rates in those exposed to metformin persists even in subgroups with impaired renal function [2, 4]. A Swedish study of 51,675 people with Type 2 diabetes found that those treated with metformin monotherapy had a lower risk of fatal or non-fatal cardiovascular disease events and all-cause mortality [2]. In a multicentre cohort of 19,691 diabetic patients with atherothrombosis, mortality rates were lower in patients treated with metformin compared to those not on metformin. This association persisted in a subgroup of patients with CKD (eGFR $30-60 \mathrm{ml} / \mathrm{min} / 1.73^{2}$ ) [4]. A recent review of metformin use in patients with kidney disease recommended that metformin could be used in patients with an eGFR of $30-60 \mathrm{ml} / \mathrm{min} / 1.73^{2}$ with dose reduction [27]. Following this review the FDA have revised their recommendation stating that it can be used in mild renal impairment and in some with moderate renal impairment [8]. It is difficult to ascertain whether the survival benefit we have shown is due to selection bias in that patients who receive metformin may be a different cohort in that they are fitter. However, we have shown that in our data patients on metformin actually had a longer duration of diabetes and higher $\mathrm{HbA}_{1 \mathrm{c}}$ levels suggesting that the survival benefit may be due to the known beneficial effects of metformin on vascular endothelium rather than selection bias.

Whilst renal safety of metformin is important in its own right, we were also motivated to analyse AKI rates as a proxy for lactic acidosis. It is difficult to ascertain the true incidence of Metformin associated lactic acidosis (MALA). Observational studies may either over or underestimate incidence of MALA [35-37]. Most cases of MALA are multifactorial with other factors contributing to lactic acidosis such as sepsis, cardiac, respiratory or hepatic failure. Studies can be subject to ascertainment bias with fitter patients being selected for treatment with metformin. In addition, patients on metformin are more likely to have lactate levels measured leading to the potential for overestimation of MALA. International Statistical Classification of Diseases and Related Health Problems 10th Revision (ICD -10) coding in isolation cannot be used in observational studies to establish cases of MALA due to a lack of specific code for lactic acidosis and many studies have not included 
patients with CKD. It is therefore difficult to establish the safety of metformin in patients with CKD. We therefore examined hospitalisations with AKI in patients treated with metformin as clinically significant lactic acidosis occurs in the presence of AKI. Whilst we cannot draw conclusions regarding the rates of MALA in patients with CKD, we have shown that metformin use does not adversely affect mortality which is reassuring. This is arguably more clinically significant than actual rates of MALA.

\section{Conclusion}

Our large cohort of metformin users provides a reassuring message of the safety of metformin in patients with or without a background of CKD and supports the recent revision of FDA and EMA guidance on metformin prescribing in patients with renal impairment. We have also demonstrated that metformin does not adversely affect survival in patients with AKI.

\section{Abbreviations}

AKI: Acute kidney injury; ARB: Angiotensin-II receptor antagonists; ATC: Anatomical therapeutic chemical; $\mathrm{CHI}$ : Community health index; CKD: Chronic kidney disease; EMA: European medicines agency; FDA: Food and Drug Administration; HIC: Health informatics centre; IQR: Interquartile range; KDIGO: Kidney disease improving global outcome; MALA: Metformin associated lactic acidosis; MDRD: Modification of diet in renal disease; NHS: National health service; NICE: National Institute for Health and Care Excellence; pyrs: Person years; SCI-DC: Scottish care initiative-diabetes collaboration; SMR01: Scottish morbidity record of hospital admissions:

SRR: Scottish renal registry

\section{Acknowledgements}

We thank the members of the Scottish Diabetes Research Network, the Scottish Renal Registry, and the SCI-DC team. Some of this data was presented in abstract form at the Diabetes UK Professional Conference 2016 and Scottish Renal Association Meeting 2016.

\section{Funding}

SB was funded by a National Health Service Research Scotland Fellowship from the Chief Scientist Office.

\section{Availability of data and materials}

Individual level data used in the project are not available for sharing as they derive form health records and so governance restrictions apply. Verification checks of the results can be done by approved third parties on site.

\section{Authors' contributions}

SB conceived and designed the study, interpreted the data, drafted the article and approved the final version of the manuscript. BF and SM acquired the data, analysed and interpreted it, revised the manuscript critically for important intellectual content and approved the final version of the manuscript. $\mathrm{HC}$ and $\mathrm{HL}$ conceived and designed the study, interpreted the data, revised the manuscript critically for important intellectual content and approved the final version of the manuscript. RM, GL, JP, PM, NS, SW, JM and $\mathrm{RL}$ contributed to conception and design, interpretation of data, revising the manuscript critically for important intellectual content and approved the final version to the manuscript. $\mathrm{HC}$ is guarantor of this work. All authors read and approved the final manuscript.

\section{Competing interests}

$\mathrm{SB}, \mathrm{BF}, \mathrm{SM}, \mathrm{HL}$ and $\mathrm{GL}$ declare no conflict of interest. SW received an honorarium from Global MedEd/ Astra Zeneca for contributing a lecture to a series of educational videos. JP is a recipient of support in kind (donation and shipping of medication to study sites) of an investigator-led trial of metformin in diabetes (REMOVAL: NCT NCT01483560) from Merck KGaA (Germany). RM has carried out advisory board work for NovoNordisk and Sanofi over the last year. $\mathrm{HC}$ and receives research support and honorarium, and is also a member of the advisory panels and speakers' bureau for Sanofi Aventis, Regeneron and Eli Lilly. JMcK received support to attend EASD from Novonordisk. He has also participated in cardiovascular risk studies with the following companies: Novo Nordisk, GlaxoSmithKline, Astra Zeneca, Boehringer Ingelheim,Merck, Sharp and Dohme and Eli Lilly. NS has consulted for Boehringer Ingelheim, Eli Lilly, Novo Nordisk, AstraZeneca, Janssen, Merck, Sanofi, and Amgen. PM is a stakeholder of Pharmatics. $\mathrm{HC}$ is a member of the Advisory Panel for Novartis Pharmaceuticals and also receives, or has recently received, research support from Roche Pharmaceuticals, Pfizer Inc., Boehringer Ingelheim, and AstraZeneca LP. $\mathrm{HC}$ is a shareholder of Roche Pharmaceuticals and Bayer.

\section{Consent for publication}

Not applicable.

\section{Ethics approval and consent to participate}

Anonymised record linkage was conducted according to Health Informatics Centre (HIC), University of Dundee [13] Standard Operating Procedure (SOP). The Tayside Research Ethics Committee does not require submission of individual studies that follow this SOP which is Caldicott Guardian approved.

\section{Publisher's Note}

Springer Nature remains neutral with regard to jurisdictional claims in published maps and institutional affiliations.

\section{Author details}

${ }^{1}$ Renal Unit, Ninewells Hospital, Dundee DD1 9SY, UK. ${ }^{2}$ Division of Population Health Sciences, School of Medicine, University of Dundee, Dundee, UK. ${ }^{3}$ Institute of Genetics and Molecular Medicine University of Edinburgh, Edinburgh, UK. ${ }^{4}$ Division of Molecular \& Clinical Medicine, School of Medicine, University of Dundee, Dundee, UK. ${ }^{5}$ Department of Medicine, University of Dundee, Dundee, UK. Institute of Cardiovascular and Medical Sciences, BHF Glasgow Cardiovascular Research Centre, University of Glasgow, Glasgow, UK. ${ }^{7}$ Centre for Population Health Sciences, University of Edinburgh Medical School, Edinburgh, UK. ${ }^{8}$ Department of Medicine, Western General Hospital, Edinburgh, UK.

Received: 17 February 2017 Accepted: 11 May 2017

Published online: 19 May 2017

\section{References}

1. Inzucchi SE, Bergenstal RM, Buse JB, Diamant M, Ferrannini E, Nauck M, Peters AL, Tsapas A, Wender R, Matthews DR, et al. Management of hyperglycemia in type 2 diabetes: a patient-centered approach: position statement of the American Diabetes Association (ADA) and the European Association for the Study of diabetes (EASD). Diabetes Care. 2012;35(6):1364-79.

2. Ekström N, Schiöler L, Svensson A, et al Effectiveness and safety of metformin in 51675 patients with type 2 diabetes and different levels of renal function: a cohort study from the Swedish National Diabetes Register. BMJ Open. 2012;2:e001076. doi:10.1136/bmjopen-2012-001076.

3. Roumie CL, Hung AM, Greevy RA, Grijalva CG, Liu X, Murff HJ, Elasy TA, Griffin MR. Comparative effectiveness of sulfonylurea and metformin monotherapy on cardiovascular events in type 2 diabetes mellitus: a cohort study. Ann Intern Med. 2012;157(9):601-10.

4. Roussel R, Travert F, Pasquet B, Wilson PW, Smith SC Jr, Goto S, Ravaud P, Marre M, Porath A, Bhatt DL, et al. Metformin use and mortality among patients with diabetes and atherothrombosis. Arch Intern Med. 2010; 170(21):1892-9.

5. Hong J, Zhang Y, Lai S, Lv A, Su Q, Dong Y, Zhou Z, Tang W, Zhao J, Cui L, et al. Effects of metformin versus glipizide on cardiovascular outcomes in patients with type 2 diabetes and coronary artery disease. Diabetes Care. 2013;36(5): 1304-11.

6. Effect of intensive blood-glucose control with metformin on complications in overweight patients with type 2 diabetes (UKPDS 34). UK Prospective Diabetes Study (UKPDS) Group. Lancet 1998, 352(9131):854-865. 
7. Glucophage (metformin hydrochloride) [final printed labeling] [www.accessdata. fda.gov/drugsatfda_docs/nda/2000/203575019_Glucophage_prntlbl.pdf]. Accessed 15 Feb 2017.

8. FDA Drug Safety Communication: FDA revises warnings regarding use of the diabetes medicine metformin in certain patients with reduced kidney function [http://www.fda.gov/downloads/Drugs/DrugSafety/UCM494140.pdf]. Accessed 15 Feb 2017.

9. Type 2 diabetes in adults: management [https://www.nice.org.uk/guidance/ ng28]. Accessed 15 Feb 2017.

10. Kajbaf F, Arnouts P, de Broe M, Lalau JD. Metformin therapy and kidney disease: a review of guidelines and proposals for metformin withdrawal around the world. Pharmacoepidemiol Drug Saf. 2013;22(10):1027-35.

11. European Medicines Agency: Use of metformin to treat diabetes now expanded to patients with moderately reduced kidney function. 14th October 2016. (http://www.ema.europa.eu/docs/en_GB/document_library/ Press_release/2016/10/WC500214248.pdf). Accessed 17 Feb 2017.

12. Kidney Disease: Improving Global Outcomes (KDIGO) Acute Kidney Injury Work Group. KDIGO clinical practice guideline for Acute kidney injury. Kidney Int Suppl. 2012:2(1):1-138.

13. Health Informatics Centre [http://medicine.dundee.ac.uk/health-informaticscentre]. Accessed 15 Feb 2017.

14. Levey AS, Coresh J, Greene T, Stevens LA, Zhang YL, Hendriksen S, Kusek JW, Van Lente F. Chronic kidney disease epidemiology C: using standardized serum creatinine values in the modification of diet in renal disease study equation for estimating glomerular filtration rate. Ann Intern Med. 2006;145(4):247-54.

15. Acute kidney injury: prevention, detection and management of acute kidney injury up to the point of renal replacement therapy (Clinical guideline 169). [http://www.nice.org.uk/guidance/CG169]. Accessed 15 Feb 2017.

16. The Scottish Care Information - Diabetes Collaboration (SCI-DC) [http:// www.sci-diabetes.scot.nhs.uk/]. Accessed 15 Feb 2017.

17. Quan $H$, Parsons GA, Ghali WA. Validity of information on comorbidity derived rom ICD-9-CCM administrative data. Med Care. 2002;40(8):675-85.

18. Perkins AJ, Kroenke K, Unutzer J, Katon W, Williams JW Jr, Hope C, Callahan CM. Common comorbidity scales were similar in their ability to predict health care costs and mortality. J Clin Epidemiol. 2004;57(10):1040-8.

19. Salpeter SR, Greyber E, Pasternak GA, Salpeter EE. Risk of fatal and nonfatal lactic acidosis with metformin use in type 2 diabetes mellitus. Cochrane Database Syst Rev. 2010:4:CD002967.

20. Bodmer M, Meier C, Krahenbuhl S, Jick SS, Meier CR. Metformin, sulfonylureas, or other antidiabetes drugs and the risk of lactic acidosis or hypoglycemia: a nested case-control analysis. Diabetes Care. 2008;31(11):2086-91.

21. Emslie-Smith AM, Boyle DI, Evans JM, Sullivan F, Morris AD, Collaboration DM. Contraindications to metformin therapy in patients with type 2 diabetes-a population-based study of adherence to prescribing guidelines. Diabet Med. 2001;18(6):483-8.

22. Kamber N, Davis WA, Bruce DG, Davis TM. Metformin and lactic acidosis in an Australian community setting: the Fremantle diabetes study. Med J Aust. 2008;188(8):446-9.

23. Kennedy L, Herman WH, Team GACS. Renal status among patients using metformin in a primary care setting. Diabetes Care. 2005;28(4):922-4.

24. Selby JV, Ettinger B, Swain BE, Brown JB. First 20 months' experience with use of metformin for type 2 diabetes in a large health maintenance organization. Diabetes Care. 1999;22(1):38-44.

25. Warren RE, Strachan MW, Wild S, McKnight JA. Introducing estimated glomerular filtration rate (eGFR) into clinical practice in the UK: implications for the use of metformin. Diabet Med. 2007;24(5):494-7.

26. Lu WR, Defilippi J, Braun A. Unleash metformin: reconsideration of the contraindication in patients with renal impairment. Ann Pharmacother. 2013;47(11):1488-97.

27. Inzucchi SE, Lipska KJ, Mayo H, Bailey CJ, McGuire DK. Metformin in patients with type 2 diabetes and kidney disease: a systematic review. JAMA. 2014; 312(24):2668-75.

28. Lalau JD, Arnouts P, Sharif A, De Broe ME. Metformin and other antidiabetic agents in renal failure patients. Kidney Int. 2015;87(2):308-22.

29. Sambol NC, Chiang J, Lin ET, Goodman AM, Liu CY, Benet LZ, Cogan MG. Kidney function and age are both predictors of pharmacokinetics of metformin. J Clin Pharmacol. 1995:35(11):1094-102.
30. Protti A, Fortunato F, Monti M, Vecchio S, Gatti S, Comi GP, De Giuseppe R, Gattinoni L. Metformin overdose, but not lactic acidosis per se, inhibits oxygen consumption in pigs. Crit Care. 2012;16(3):R75.

31. Cucchiari D, Podesta MA, Merizzoli E, Calvetta A, Morenghi E, Angelini C, Ponticelli C, Badalamenti S. Dose-related effects of metformin on acid-base balance and renal function in patients with diabetes who develop acute renal failure: a cross-sectional study. Acta Diabetol. 2016;53(4):551-8.

32. Bell S, Dekker FW, Vadiveloo T, Marwick C, Deshmukh H, Donnan PT, Van Diepen M. Risk of postoperative acute kidney injury in patients undergoing orthopaedic surgery-development and validation of a risk score and effect of acute kidney injury on survival: observational cohort study. BMJ. 2015;351:h5639.

33. Bucaloiu ID, Kirchner HL, Norfolk ER, Hartle JE 2nd, Perkins RM. Increased risk of death and de novo chronic kidney disease following reversible acute kidney injury. Kidney Int. 2012:81(5):477-85.

34. Uchino S, Bellomo R, Bagshaw SM, Goldsmith D. Transient azotaemia is associated with a high risk of death in hospitalized patients. Nephrol Dial. 2010;25(6):1833-9.

35. Lalau JD. Lactic acidosis induced by metformin: incidence, management and prevention. Drug Saf. 2010;33(9):727-40.

36. Lalau JD, Race JM. Lactic acidosis in metformin therapy: searching for a link with metformin in reports of 'metformin-associated lactic acidosis'. Diabetes Obes Metab. 2001;3(3):195-201.

37. Kajbaf F, Lalau JD. The criteria for metformin-associated lactic acidosis: the quality of reporting in a large pharmacovigilance database. Diabet Med. 2013;30(3):345-8.

\section{Submit your next manuscript to BioMed Central and we will help you at every step:}

- We accept pre-submission inquiries

- Our selector tool helps you to find the most relevant journal

- We provide round the clock customer support

- Convenient online submission

- Thorough peer review

- Inclusion in PubMed and all major indexing services

- Maximum visibility for your research

Submit your manuscript at www.biomedcentral.com/submit

) Biomed Central 